\title{
Expanded TMS Awards Program Boosts Early Careers
}

Many professional awards focus almost exclusively on past accomplishments. Investing in future possibilities, by contrast, is the intent of the growing collection of recognition opportunities for young professionals made possible by the TMS Foundation.

In the last year alone, TMS has tripled the original size of its Young Leader Professional Development Award program, added a second prestigious Early Career Faculty Fellowship, and developed a new collaboration in support of international scholarship. Advancing the professional growth of TMS's young members is also a key element of a new TMS Foundation signature program that is currently under discussion by society leadership.

Hani Henein, 2014 TMS president, said these initiatives build on an organizational culture that has long been welcoming and supportive of early career professionals. "TMS is an extremely memberfocused organization, which means as a young professional, you have many avenues to present your ideas and then pursue them. That's what got me involved when I first became a member of TMS," he said. "Early in your career, though, there are a number of considerations that you have to address as you become involved with a professional society and begin to develop your network of colleagues. Through the work of the TMS Foundation, TMS has made it a priority to 'smooth the way,' so that young scientists and engineers can take full advantage of what being a member of TMS means, and look to TMS as their professional 'home."”

The following pages introduce this year's group of TMS members who have been recognized for their potential as future leaders within the society and the professions it serves. While they were formally honored at the TMS 2014 Annual Meeting and Exhibition (TMS2014) in February, please make a point of including them in your network of colleagues in the months to come as they embark on this stage of their professional journeys.

\section{TMS Young Leader Professional Development Award Winners}

\section{ELECTRONIC, MAGNETIC \& PHOTONIC MATERIALS DIVISION}

\section{Saryu Fensin}

Fensin is a postdoctoral researcher at Los Alamos National Laboratory, having earned a degree in chemistry with a minor in physics at Mount Holyoke College and a Ph.D. in materials engineering at the University of California, Davis. She has been actively involved with several TMS committees for the past three years, and has served as secretary of the Young Professionals Committee. Fensin has held leadership posts at Mount Holyoke and Los Alamos as well, and is the recipient of more than a dozen scholarships and awards. "The generous support of the TMS Foundation allows me to continue to participate in the society," said Fensin. "TMS is an incredible avenue to network with other young professional peers, as well as seasoned professionals. This award provides me with additional networking opportunities that will not only provide me additional insights into the inner workings of TMS, but also help me learn about other ways to contribute to my profession."

\section{Yan Li}

Li joined Intel Corporation in 2006 as a senior package failure analysis engineer. She received her B.S. and M.S degrees in physics from Peking University, Beijing, China, and her Ph.D. in materials science and engineering from Northwestern University. $\mathrm{Li}$ is an active TMS member, having served as conference organizer and session chair of the Electronic Packaging and Interconnection Materials Committee, among other roles. "This award opens a door for me. The invitation to attend the TMS Board of Directors meeting will be very helpful to further developing my leadership skills," Li said. "The invitation to attend the EMPMD Council meeting will also help me prepare for becoming a future leader within the professional society."

\section{Shih-kang Lin}

Lin is an assistant professor in the Department of Materials Science and Engineering at National Cheng Kung

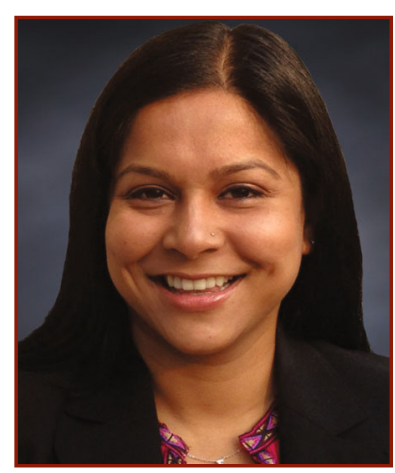

Saryu Fensin

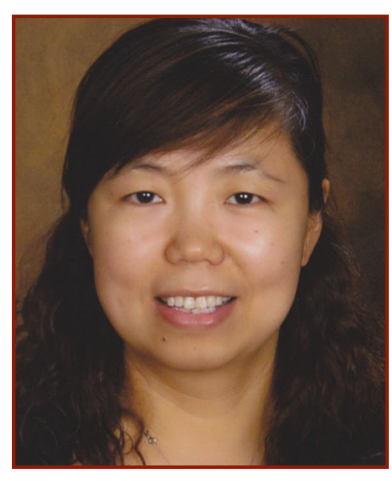

Yan Li 


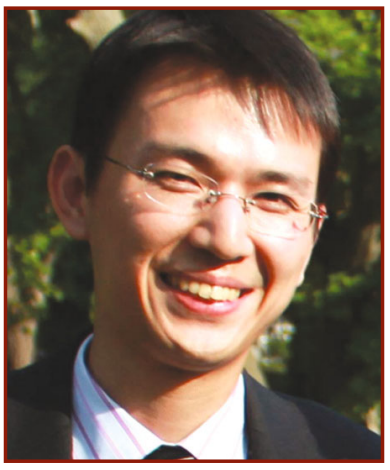

Shih-kang Lin

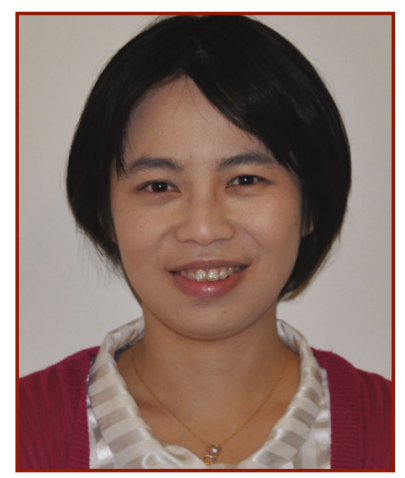

Fan-Yi Ouyang

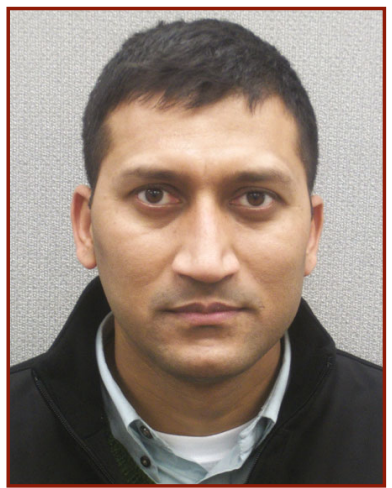

Amit Pandey

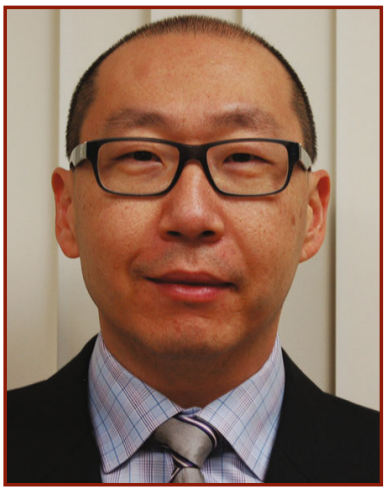

Hans Shin
University in Taiwan. He received his

Ph.D. in chemical engineering at National

Tsing Hua University, and has worked as a visiting scholar at the Institute of Scientific and Industrial Research (ISIR) of Osaka University in Japan, a visiting scholar at the Pennsylvania State University, and a research associate at the University of Wisconsin, Madison. His research focuses on materials thermodynamics, phase equilibria, and phase transformation using experimental skills as well as computational approaches. Lin said the Young Leader award encourages him to be further dedicated to materials research, education, and service with and through TMS. "With this prestigious honor from TMS at this early stage of my career, I am highly motivated to pursue more interactions with materials scholars around the world," he said.

\section{Fan-Yi Ouyang}

Ouyang adds another honor to a long list of achievements, having been recently recognized with awards for excellence in research and teaching at National Tsing Hua University, Taiwan, where she has been an assistant professor in the Department of Engineering and System Science since August 2010. She received her B.S. and M.S. degrees from the same university, and earned her Ph.D. in materials science and engineering from the University of California, Los Angeles. She has also worked as a reliability and quality engineer at Intel Corporation. "TMS has provided me invaluable opportunities to contribute my research expertise and exchange the ideas with international experts. It also helps me
"This award opens a door for me. The invitation to attend the TMS Board of Directors meeting will be very helpful to further developing my leadership skills."

\section{-Yan Li, Intel Corporation}

build more contacts with people working in my fields," Ouyang said. "Because of this award, I will be able to be involved in more society activities, which will strengthen my leadership skills and enhance my professional career development."

\section{Amit Pandey}

Pandey is a development lead in the reliability division of Rolls Royce LG Fuel Cell Systems, Inc. Prior to this, he was postdoctoral fellow at Johns Hopkins University, and postdoctoral research associate at the Oak Ridge National Laboratory. Pandey received his Ph.D. in mechanical engineering from the University of Maryland, an M.S. in civil engineering from the University of Arizona, and a B.Tech. in mining engineering from the Indian Institute of Technology. "TMS membership has provided me opportunities for networking and collaboration with scholars in both academia and industry. I look forward to many other exciting programs," he said.

\section{Hans Shin}

Shin is a materials engineer at Pacific Testing Laboratories, where he is vice president and manager of the failure analysis and chemical laboratories. $\mathrm{He}$

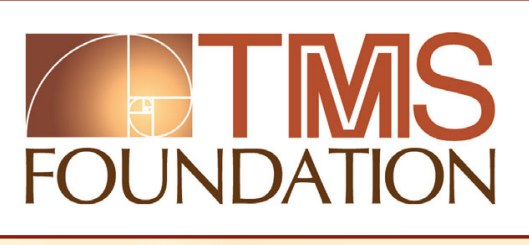

\section{Invest in the Future} of Your Profession

Many TMS members point to the support that they received through the TMS Young Professional Program as an important milestone in the development of their careers. Be part of the many success stories that are still to come by supporting the TMS Foundation. Visit the Foundation website at www.TMSFoundation.org to learn more and to make an online donation. For questions or to make a donation by phone or mail, contact Mary Samsa, TMS Foundation \& Public Affairs Manager at msamsa@tms.org. 
is involved with materials testing and characterization of both metallic and nonmetallic materials, as well as litigation support and failure analysis. He received his master's degree in materials engineering from California State University,

Northridge and his undergraduate degree in environmental toxicology, with an emphasis in analytical chemistry, from the University of California, Davis. "This award will give me the opportunity to see the inner workings of various technical committees from a structural and organizational standpoint," Shin said. "I hope to act as a liaison between technical professionals and students for the development of future young professionals and look forward to volunteering at future meetings."

\section{Eva Zurek}

Zurek began her current position as an assistant professor in the Department of Chemistry at the University at Buffalo, SUNY, in 2009. She performed her doctoral work at the Max Planck Institute for Solid State Research in Stuttgart,

"I hope to act as a liaison between technical professionals and students for the development of future young professionals and look forward to volunteering at future meetings."

\section{-Hans Shin, Pacific Testing} Laboratories

\section{Are You the Next TMS Young Leader?}

The TMS Young Leader Professional Development Award program was created to groom young professionals for future leadership positions within TMS by offering them opportunities to become more involved in society activities and to network with prominent TMS members. Chosen from each of the five TMS technical divisions, the award winners receive support from the TMS Foundation to attend a TMS annual meeting, as well as access to networking opportunities and an invitation to attend TMS Board of Directors and division council meetings.

Any professional TMS member age 40 and under is eligible to apply for this award. The deadline for applications for the next round is August 15, 2014. Additional information and the application form can be accessed at the TMS Professional Honors and Awards website at awards.tms.org.

Germany, and went on to a postdoctoral appointment at Cornell University, where she received the prestigious 2013 Alfred P. Sloan Research Fellowship. Zurek said the TMS award will be extremely beneficial in helping her advance her career. "I will be provided with the opportunity to meet and network with other TMS members so that I can showcase the research carried out in my group. These interactions will undoubtedly lead to future collaborations, whether they be scientific or organizational within the TMS," she said. "The annual conference allows me to learn about the most recent progress in my scientific field of interest, as well as important topics related to industry and government policy."

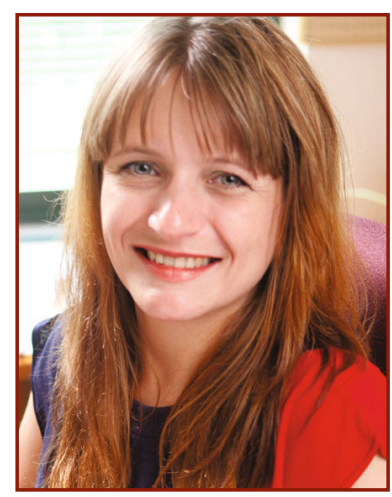

Eva Zurek

\section{EXTRACTION \& PROCESSING DIVISION}

\section{Salvador Barriga}

Barriga is a research engineer and technical leader of the anodes and aluminum research groups at Infinium. Prior to joining Infinium, he earned his Ph.D. in materials science and engineering from the Massachusetts Institute of Technology (MIT). While a graduate student, Barriga also was involved part-time at MIT Lincoln Laboratory, where he optimized the process used to measure and characterize the afterpulsing effect of single-photon avalanche photodiodes. He has earned a number of awards, including the John Wulff Award for excellence in teaching from his department at MIT. Barriga

earned his B.A. in physics with high honors from the University of California, Berkeley, and his A.S. in physical science from Modesto Junior College. Noted Barriga, "I am looking forward to contributing my experiences and adding to the diversity of TMS. This experience will be a catalyst for my professional growth."

\section{"I am looking forward to contributing my experiences and adding to the diversity of TMS. This experience will be a catalyst for my professional growth."}

- Salvador Barriga, Infinium

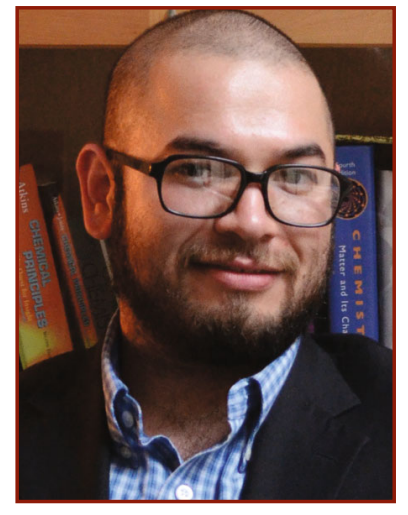

Salvador Barriga 


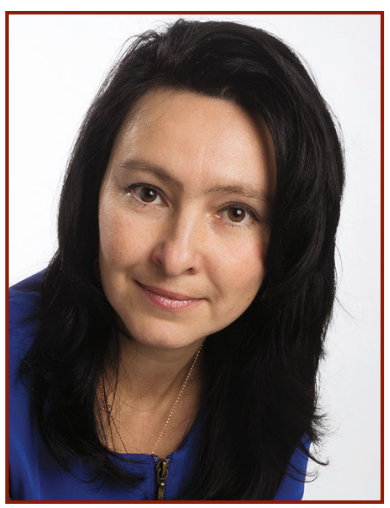

Yulia Meteleva-Fischer

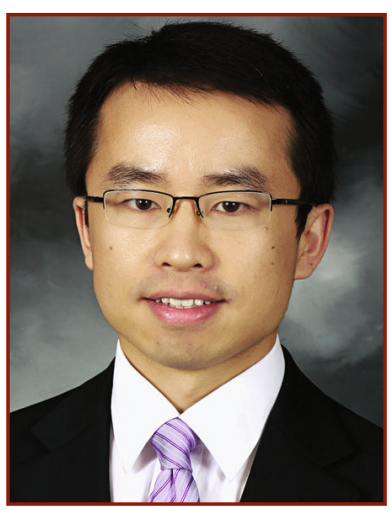

Zhiwei Peng

\section{Yulia Meteleva-Fischer}

Meteleva-Fischer hopes her award will help her bring further attention to making solar energy accessible for everyone. She started her career path at Voronezh State University in Russia, where she earned both bachelor's and master's degrees in general and applied chemistry. Her work on properties of charge carriers in solid solutions of cadmium-zinc sulfides earned Meteleva-Fischer her Ph.D. in physical chemistry from the Institute of Problems of Chemical Physics at the Russian Academy of Sciences (IPCP RAS), as well as two national awards. For the last five years, Meteleva-Fischer has been a postdoctoral researcher with the Materials Innovation Institute in the Netherlands. "TMS offers excellent opportunities for scientific communication - It brings academic and industrial people together through the organizing conferences, discussions in the scientific committees, and professional awards," she said.

"Personally, I benefit by presenting my research results, building a research network through organizing the Solar Cell
Silicon symposium, and attending the keynote lectures."

\section{Zhiwei Peng}

Peng is a guest editor this year for $J O M$ and has been on the editorial board of the Journal of Minerals and Materials Characterization and Engineering since 2012. He is currently a research assistant professor in the Department of Materials Science and Engineering, Michigan Technological University. He received a B.Eng. degree in mineral processing engineering and M.S. degree in ferrous metallurgy from Central South University, and his Ph.D. in materials science and engineering from Michigan Technological University. "I became a TMS member when I was a graduate student, and have enjoyed attending TMS conferences ever since," Peng said. "The impact of TMS on my career through its sponsored meetings and publications is truly immeasurable. I am thrilled and humbled to be recognized by the society with such an incredible honor."
"TMS offers excellent opportunities for scientific communication-It brings academic and industrial people together through the organizing conferences, discussions in the scientific committees, and professional awards."

- Yulia Meteleva-Fischer, Materials Innovation Institute, Netherlands

\section{LIGHT METALS DIVISION}

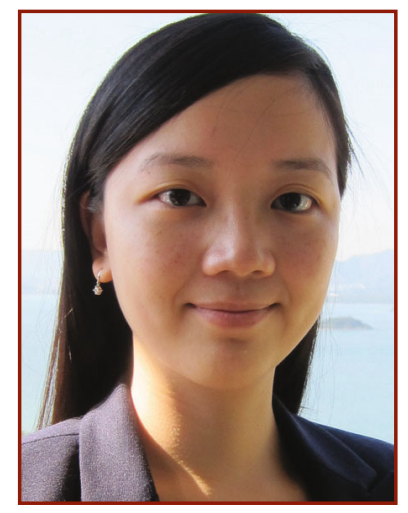

Cheuk Yi Cheung

\section{Cheuk Yi Cheung}

Cheung is currently a postdoctoral fellow at the University of New South Wales. She received her B.Eng. in industrial chemistry with first class honor, and her $\mathrm{Ph} . \mathrm{D}$. in chemical engineering, from the same university. Her particular research interests are conceptual modeling and signal processing for the aluminum smelting process. "TMS has been very important for my research career so far and this award will benefit me in different ways," she said. "It will give more exposure of my work, and, more importantly, it will be a springboard for my career and establish me as a true leader in the light metal fields. This great honor will open doors, and I look forward to learning more from the world's best at the TMS annual meetings."

\section{In-Ho Jung}

Jung joined the Department of Mining and Materials Engineering at McGill University as an associate professor after a career as a senior researcher at Research Institute of Industrial Science and Technology in South Korea. He was also a founding member of Posco Magnesium. His expertise is computational thermodynamic database development and applications to material design and process design, and he has authored or coauthored more than 150 journal papers and conference papers. He received the NSERC Leo Derikx Synergy Award in 
"TMS has been very important for my research career so far and this award will benefit me in different ways."

\section{- Cheuk Yi Cheung, University of New South Wales, Australia}

2013 for his contribution to industrial process development, and the HelmholtzZentrum Geesthacht Magnesium Research Award 2013. "I believe this award will help me to develop my career even further as a materials scientist," he said. "Through the many opportunities given to me, I will be more involved in TMS activities and build a wider networking group. This award opens a new chapter of my career."

\section{Nicholas Kirkland}

Kirkland began his current position as an assistant professor at Nagasaki University in Japan after graduating with a master's degree in design, management and manufacturing engineering from the University of Durham, England, and completing a Ph.D. in biomedical/ biomaterials engineering from the University of Canterbury, New Zealand. His Ph.D. research focused on biodegradable magnesium alloys for use as implant materials, specifically in orthopedics and stents. "This award provides me with an excellent opportunity to participate in what is the most important materials engineering meeting of the year. As a young researcher, it is often hard to secure funds and assistance to attend important scientific meetings," he said. "I am extremely honored to have received this award from the TMS Foundation, and believe that its goal to develop and fund programs to help future leaders in materials roles is absolutely vital and is a cornerstone of the TMS mission as a whole."

\section{Zhenke Teng}

Teng has been an active member of TMS since 2008, participating in four annual meetings, presenting seven technical papers, and winning the TMS student poster award in 2010 . He is currently a research engineer at the automotive center of United States Steel Corporation. Teng worked as a postdoctoral research associate at Oak Ridge National Laboratory, after graduating from the University of Tennessee with a Ph.D. in materials science and engineering. He received the university's Chancellor's Award for extraordinary professional promise and Graduate Student Award for excellence in research. His publications can be found in Acta Materialia, Scripta Materialia and many other leading journals. "TMS has been giving me the opportunity to attend annual conferences over the past five years. From my experiences, I have learned a lot, not only in terms of technical knowledge, but also communication skills with other professionals," Teng said.

\section{David Sydney Wong}

Wong is currently a project manager at the Light Metals Research Centre at the University of Auckland, New Zealand, having recently completed a Ph.D. in chemical and materials engineering there. Wong led the completion of the center's Fluoride Emissions Management Guide (FEMG) and its implementation in a Chinese smelter. He has also taken a lead role in the center's research of continuous greenhouse gas emissions and automatic anode effect termination (AET) strategies for aluminum smelters. Wong said his Young Leader Award would not have been possible without the support of his peers, managers, and mentors. He added, "It will provide many opportunities to build new contacts and networks with other TMS leaders in my industry. It will also be a privilege to see how TMS's board members steer the future of such an important organization. Financially, this award will make it possible to manage the significant travel costs to fly from New Zealand to the United States to attend the TMS annual meeting."

"I am extremely honored to have received this award from the TMS Foundation, and believe that its goal to develop and fund programs to help future leaders in materials roles is absolutely vital and is a cornerstone of the TMS mission as a whole."

- Nicholas Kirkland, Nagasaki University, Japan

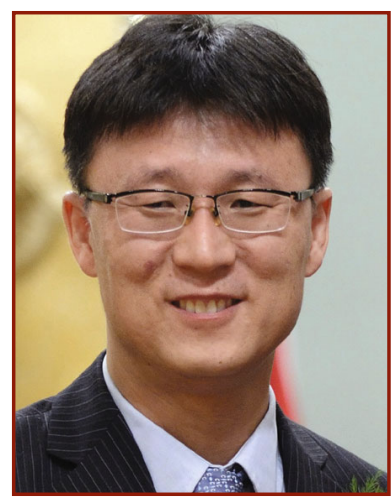

In-Ho Jung

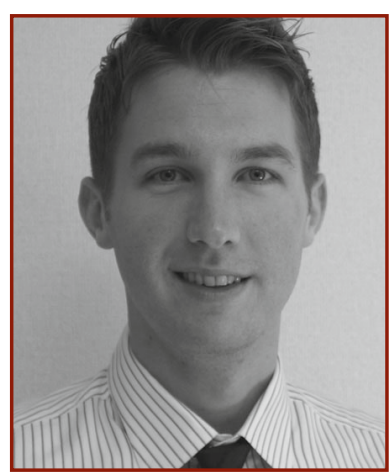

Nicholas Kirkland

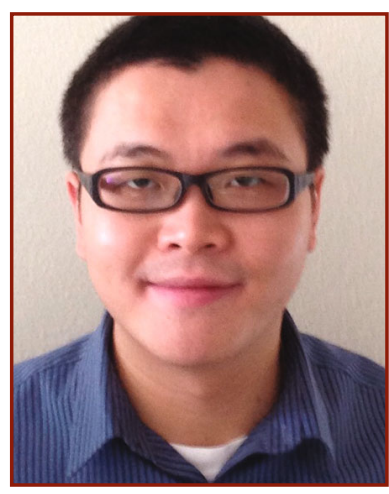

Zhenke Teng

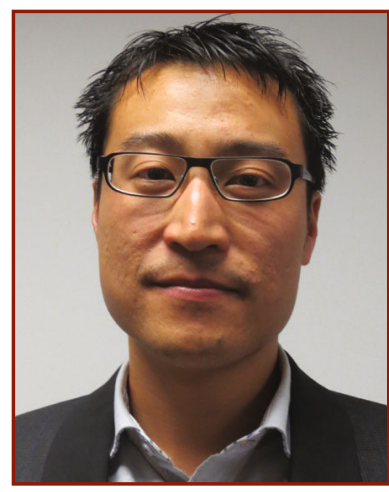

David Sydney Wong 


\section{MATERIALS PROCESSING \& MANUFACTURING DIVISION}

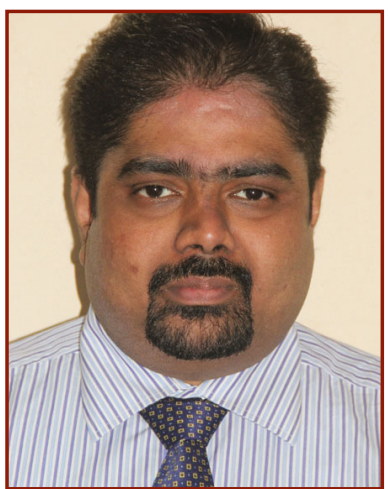

Srinivasa Rao Bakshi

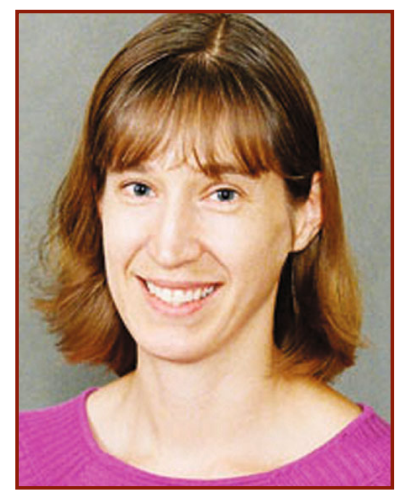

Amber Genau

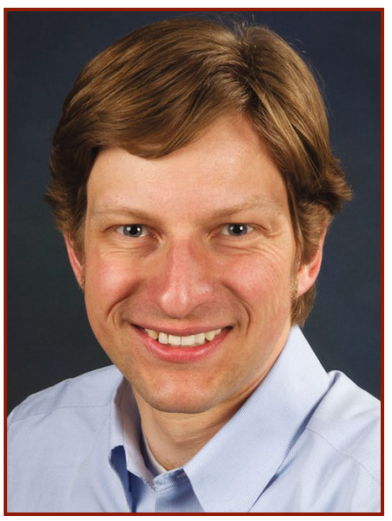

Paul Gibbs

\section{Srinivasa Rao Bakshi}

Bakshi is an assistant professor in the Department of Metallurgical and Materials Engineering at India Institute of Technology Madras. He earned a $\mathrm{Ph} . \mathrm{D}$. in materials engineering from Florida International University, a B.Eng. in metallurgical engineering from the National Institute of Technology, Rourkela, India, and an M.Eng. degree in metallurgy from the Indian Institute of Science, Bangalore. Bakshi worked as a scientific offficer in Bhabha Atomic Research Centre in Mumbai and has co-authored a book, Carbon Nanotube Reinforced Metal Matrix Composites. $\mathrm{He}$ is currently the vice chair of the TMS Surface Engineering Committee. "Since my student days, I have benefitted by being a member of TMS. I look forward to participating in the annual meetings to present my work, meet people, listen to wonderful talks, and get inspired and charged up," he said. "TMS gave me an opportunity to serve in leadership activities, and helped me to organize symposiums and connect with researchers from all over the world. I look forward to contributing to the activities of TMS in an increased capacity and making it an organization with global presence."

\section{Amber Genau}

Genau received a B.S. and M.S. in materials engineering from Iowa State University and completed her Ph.D. at Northwestern University in materials science and engineering. For her Ph.D., she worked on a NASA-funded project studying coarsening behavior in microgravity and developing methods to quantify changes in complex $3 \mathrm{D}$

"I am very grateful to the TMS Foundation for making it possible for me to remain connected to the society and my research community during this period of my career."

-Amber Genau, University of Alabama, Birmingham microstructures. She spent two years as a guest scientist at the German Aerospace Center in Cologne, working in the Institute for Materials Physics in Space. In 2010, she accepted a position as an assistant professor in the Materials Science and Engineering Department at the University of Alabama, Birmingham. Genau is an active member of TMS, participating in the Solidification Committee and Young Professional Committee, and serving as faculty advisor for the University of Alabama Material Advantage chapter. "I have been a member of TMS since I was an undergraduate, and the annual meeting has always been the primary technical conference that I attend each year," she said. "As a new faculty member, this award makes it possible for me to continue attending even though I don't yet have funded research to pay for conference travel. I am very grateful to the TMS Foundation for making it possible for me to remain connected to the society and my research community during this period of my career."

\section{Paul Gibbs}

Gibbs is a postdoctoral research associate in the materials science and technology division at Los Alamos National Laboratory, where he studies the influence of imposed processing variations on solidification microstructure evolution using real-time $\mathrm{x}$-ray and proton imaging. He earned his B.S. and $\mathrm{Ph}$.D. in metallurgical and materials engineering from the Colorado School of Mines. For his Ph.D. research at the university's Advanced Steel Processing and Products Research Center, Gibbs investigated the role of metastable austenite on the deformation behavior of emerging third-generation advanced high strength steels. "TMS provides a special venue where the challenges and opportunities facing materials research can be openly discussed between members of academia, industry, and national laboratories. This accelerates the discovery of novel materials solutions through professional collaboration," said 
Gibbs. "The personal relationships forged within TMS make up the structure that ensures lasting strength to our profession, and I am excited to contribute to this dynamic group."

\section{J. Brian Jordon}

Jordon's research interests include microstructure-based constitutive modeling of plasticity and damage, fatigue modeling, fracture mechanics, experimental quantification of structureproperty relationships, and advanced joining technologies for lightweight materials. He has published more than 40 peer-reviewed journal and conference papers in these and related areas. Jordon is currently an assistant professor in the Department of Mechanical Engineering at The University of Alabama. Prior to this, he was an interim associate director and an assistant research professor at the Center for Advanced Vehicular Systems (CAVS) at Mississippi State University, where he received his Ph.D. in mechanical engineering. "This award will give me the opportunity to continue to improve my leadership skills and to learn about the society. TMS is a great organization and provides an excellent platform to present my research and to meet fellow colleagues," said Jordon.

\section{Lan Li}

$\mathrm{Li}$ is an assistant professor of materials science and engineering at Boise State University. She earned her doctorate in nanomaterials at the University of Cambridge, followed by working in the Bio-Nano Electronic Research Center at Toyo University in Japan. She conducted her research as a post-doctoral associate on the theoretical and computational studies of metal-fullerene nano-systems, hydrogen-storage materials, and metal oxide thin films at the Department of Physics, University of Florida. She then joined the Center for Materials Informatics at Kent State University and, for her achievements in computational materials science, was subsequently awarded a senior fellowship at the U.S. National Institute of Standards and Technology to work on energy and sustainability. She is vice chair of the TMS Education Committee, as well as a member of the TMS Integrated Computational Materials Engineering Committee. "This award and the TMS Foundation provide a great opportunity for me to network and make connections with peers and the younger members of TMS," said Li.

\section{Nan Li}

$\mathrm{Li}$ is a staff scientist at Los Alamos National Laboratory, where he also did his postdoctoral research. He earned his B.S. in materials science from the Beijing University of Chemical Technology, and his master's in the same field at the Institute of Metal Research in China. $\mathrm{Li}$ received a Ph.D. in materials science from Texas A\&M University. "Since I first attended the TMS annual meeting as a graduate student in 2008, I was deeply impressed because it provided a great opportunity to interface with peers and senior professionals," noted Li.

"Active involvement in TMS is a great experience to improve interpersonal skills and establish collaboration, all the while advancing my career development. Winning this award also increases my enthusiasm to help other young scientists further their careers through TMS-related programs."
"TMS provides a special venue where the challenges and opportunities facing materials research can be openly discussed between members of academia, industry, and national laboratories. This accelerates the discovery of novel materials solutions through professional collaboration."

—Paul Gibbs, Los Alamos National Laboratory

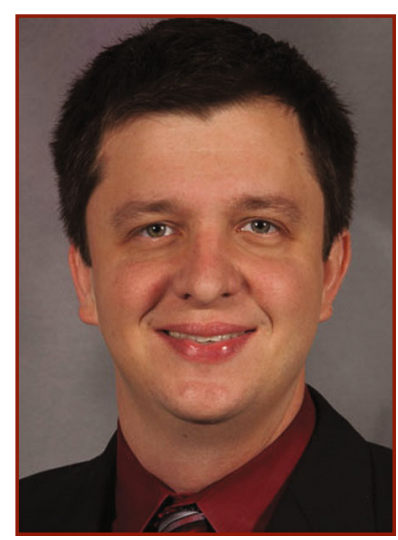

J. Brian Jordon

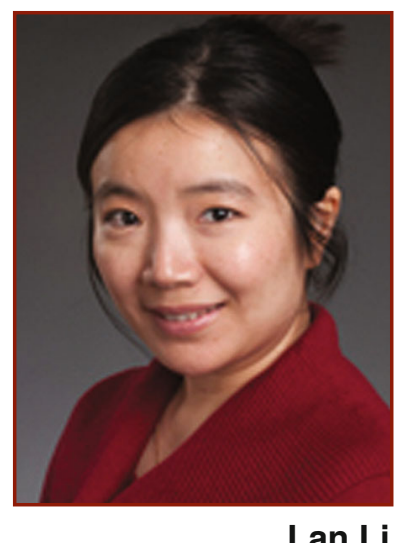

Lan Li

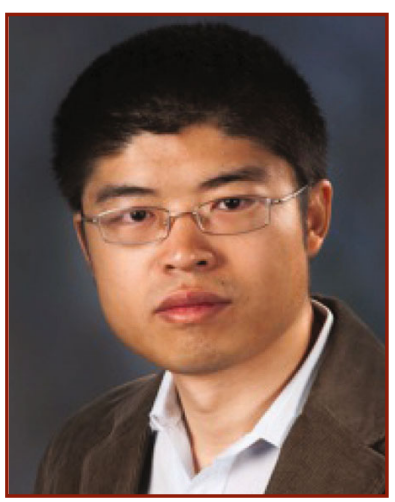

Nan Li 


\section{STRUCTURAL MATERIALS DIVISION}

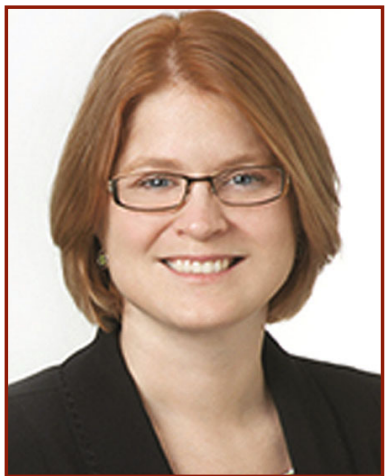

Jennifer Carter

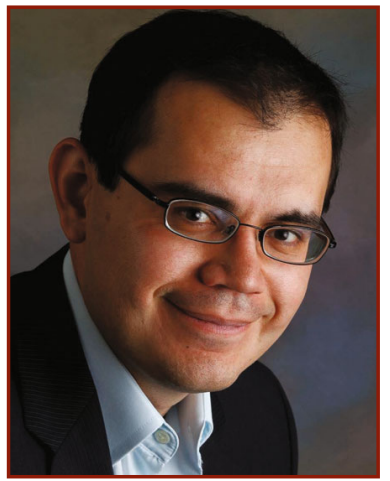

Juan Pablo Escobedo

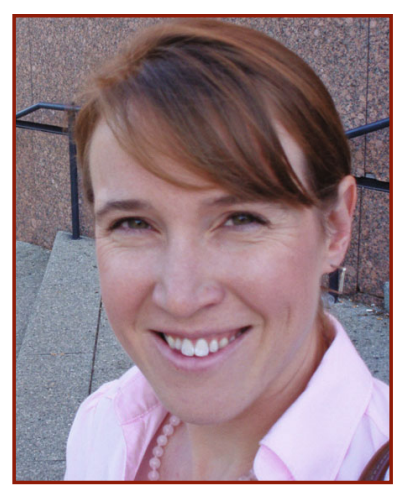

Jessica A. Krogstad

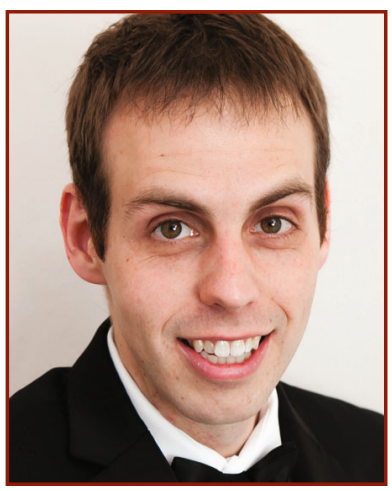

Benjamin Morrow

\section{Jennifer Carter}

Carter joined the Case Western Reserve

University faculty as an assistant professor in the Materials Science and Engineering Department in 2013. She received her $\mathrm{Ph} . \mathrm{D}$. at The Ohio State University after completing her B.S. and M.S. at the University of California, Davis. She also spent time with the metals joining and processing branch at NASA Marshall Space Flight Center in Huntsville, Alabama. Carter has been a member of TMS since 2007, when she joined her university's Material Advantage Chapter. She is an active volunteer, helping organize symposia associated with the Mechanical Behavior of Materials Committee, chairing technical sessions, and helping advance TMS strategic goals of diversity, student involvement, and early career development. "This award will allow me to more readily participate in the outreach and diversity activities that help grow the TMS community," Carter said. "I look forward to learning more about how the TMS programing committees work within the guidelines and goals of the TMS Board of Directors. I appreciate that the TMS Foundation believes that helping advance my career goals also advances the TMS community."

\section{Juan Pablo Escobedo}

Escobedo is currently a lecturer in the School of Engineering and Information Technology at the University of New South Wales, Australia. He earned his Ph.D. in mechanical engineering at Washington State University (WSU). Escobedo has also held research positions at WSU's Institute for Shock Physics and Los Alamos National Laboratory. His main research interests center on the dynamic behavior of materials under extreme conditions, particularly high pressure and high strain rate. "I feel very fortunate to receive this award," said Escobedo. "I believe it will further strengthen my involvement with TMS, and, as a result, will enhance my academic career development."

\section{Jessica A. Krogstad}

Krogstad is a postdoctoral scholar in the
Department of Mechanical Engineering at Johns Hopkins University. She will be joining the faculty in the Department of Materials Science and Engineering at the University of Illinois, UrbanaChampaign - where she received her B.S. in materials science and engineering - as an assistant professor in August 2014. Krogstad earned her Ph.D. in materials at the University of California, Santa Barbara. Her research utilizes electron microscopy and novel micro-mechanical tests to investigate the link between microstructural and phase evolution and the resulting impact on mechanical performance of structural materials in harsh environments. "I received one of my first undergraduate scholarships from TMS - an award that stimulated my curiosity and helped direct me towards my current career path," said Krogstad. "I am looking forward to participating in the TMS annual meeting at a level I've not experienced before. I am confident that this experience will be very positive for me, hopefully leading to many networking opportunities, scientific exchanges and a chance to better serve our scientific community."

\section{Benjamin Morrow}

Morrow is a postdoctoral research associate at Los Alamos National Laboratory, where his research focuses on characterization of materials and structure-property relationships in metals. He earned a Ph.D. in materials science and engineering from The Ohio State University. He has been a member of TMS since 2003, and serves on the Mechanical Behavior of

"I received one of my first undergraduate scholarships from TMS-an award that stimulated my curiosity and helped direct me towards my current career path. I am looking forward to participating in the TMS annual meeting at a level l've not experienced before." Johns Hopkins University 
Materials, Titanium, Young Professionals, and Women in Science committees. "From the time I joined as a student, TMS has been immeasurably valuable to me, both for technical content and career development," said Morrow, "The TMS Foundation, through its numerous programs and recognitions, plays a critical role in supporting and promoting young professionals, and sculpting them into future leaders of the materials field. I am excited to have the opportunity to learn more about TMS, and to leverage my experiences with the society to more fully give back to the scientific community."

\section{John Nychka}

Nychka fills several roles in the School of Dentistry at the University of Alberta: associate professor in chemical and materials engineering, associate chair of undergraduate studies, and adjunct associate professor. He received his B.Sc. from the University of Alberta in metallurgical engineering, his M.Eng. in materials science and engineering from McMaster University, and his Ph.D. in materials from the University of California, Santa Barbara. Nychka has been active in professional societies such as TMS through organization of symposia, serving in various executive positions, chairing committees, and providing student mentorship as a faculty advisor of Material Advantage. He has also served as a guest editor of special issues in journals such as $J O M$ and MSE C. "The many initiatives which the TMS Foundation supports have often benefitted colleagues and students at the universities where I have worked. This award will allow me to see beyond the technical programming and day-to-day goings on within committees and look more toward division involvement and planning of the future of the society," he said. "I hope I can contribute positively and eventually be able to help others become involved and engaged within TMS."

\section{Corinne Packard}

Packard joined the Metallurgical and Materials Engineering Department at the Colorado School of Mines as an assistant professor in 2010, and holds a joint appointment at the U.S. National Renewable Energy Laboratory in the
National Center for Photovoltaics. She earned her Ph.D. in materials science and engineering from the Massachusetts Institute of Technology. Her current research advances an understanding of relevant issues in the mechanical behavior of materials in renewable and traditional energy sources. "The Foundation's commitment to supporting and encouraging students and young professionals to become active participants in the society early on in their careers is generous, and provides meaningful networking experiences," said Packard. "This support allows me to further develop as a recognized professional in the field. I look forward to the opportunity to interact with the leadership of TMS at the annual meeting and to hear all that has been going on in the TMS scientific community in the last year."

\section{Michael R. Tonks}

Tonks is a staff scientist at the Idaho National Laboratory, where he completed a year as a postdoctoral researcher developing multiphysics models of microstructure evolution in irradiated materials, He earned a Ph.D. in mechanical engineering from the University of Illinois, Urbana-Champaign, with his research focused on stochastic methods for crystal plasticity. Tonks spent the last three years of his Ph.D. at Los Alamos National Laboratory as a graduate research assistant. $\mathrm{He}$ is the creator and lead developer of the mesoscale MARMOT code, the signature mesoscale code for the U.S. Department of Energy Nuclear Energy Advanced Modeling and Simulation (NEAMS) program. "TMS is the premier materials science professional organization, and since becoming a member in 2009, I have benefited by my membership. The JOM journal is a professional and enriching publication, and I enjoy the technical content and the networking that I find at each annual meeting," said Tonks. "This award will assist me in becoming more involved in TMS, which will help my professional development and allow me to give back to the field through service."

This article was compiled by Lynne Robinson, JOM Contributing Editor, Taitia Shelow, freelance writer, and Deborah Price, TMS Awards and Recognition Specialist
"I appreciate that the TMS Foundation believes that helping advance my career goals also advances the TMS community."

-Jennifer Carter, Case Western

Reserve University

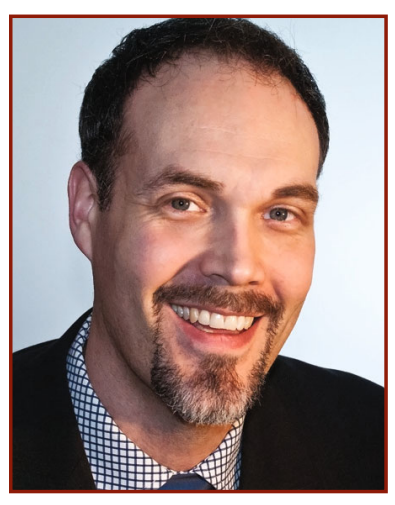

John Nychka

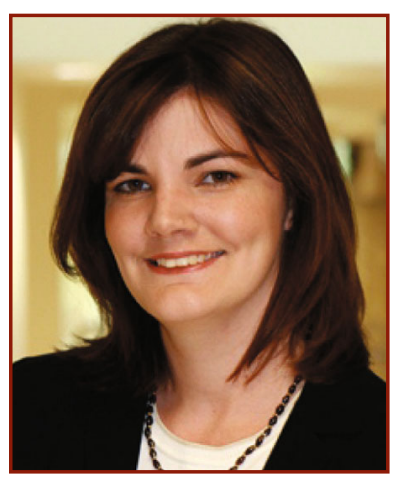

Corinne Packard

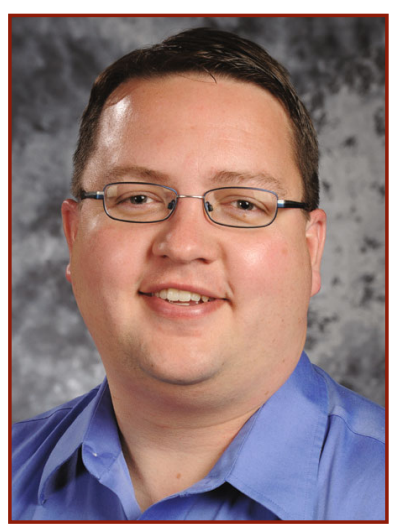

Michael R. Tonks 


\section{And Then There Were Two: The TMS Early Career Faculty Fellow Award}

Since its inception in 2007, the Early Career Faculty Fellow (ECFF) program has evolved into one of the most competitive awards that TMS offers. To broaden access to this unique professional development opportunity, the TMS Foundation earmarked support for a second ECFF award in 2014. Aimed at individuals employed in the tenure-track position of assistant professor or equivalent, the ECFF serves the dual purposes of recognizing professional accomplishment while also providing award recipients with the technical and financial support to contribute to TMS activities, as well as their own

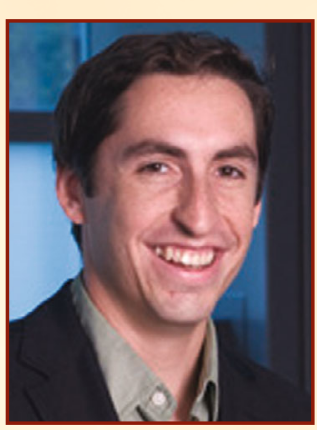

Daniel Santiago Gianola professional development. Award requirements include attending two TMS annual meetings, making a brief presentation at the Young Leader Tutorial Luncheon Lecture in the first year of the award, and organizing a symposium during the second year.

"TMS has always been a great home for materials researchers like myself looking to make a longlasting and sustained impact in the field, and I feel proud to be a TMS member. I'm truly appreciative of this recognition, which gives me a renewed sense of vigor for the wonderful field of materials science and engineering," said Daniel Santiago Gianola, Skirkanich Assistant Professor of Materials Science and Engineering, University of Pennsylvania (Penn), and one of the 2014 ECFF award winners. Gianola teaches undergraduate and graduate courses, while also directing a research group focused on understanding, modeling and predicting the mechanical response of advanced materials at reduced length scales.

"The visibility and public perception of the field of materials science and engineering has never been higher. Coupled with an incredibly bright and motivated student body at Penn, it is an exciting time to be a researcher and educator in our field," said Gianola. "My involvement with scholars at all levels - in the classroom, through advising of research projects, by mentoring of budding scientists and engineers, and through numerous outreach activities - fuels my passion for the teaching and research trade."

Gianola's Young Leader Tutorial Luncheon Lecture at TMS2014 was "Fostering International Interactions and Collaborations in Materials Science and Engineering." His discussion examined strategies to "defeat parochial views to research and education, mechanisms for engagement in international activities, and opportunities for student exchange and promoting global citizenship in the next generation of scientists and engineers." Gianola explained that the topic is strongly rooted in his own experience, saying, "I've been very privileged to have been exposed to formative opportunities for international research collaborations during most periods of my career. These have shaped my perspective on research and what it means to be a scientist."

"Back to Basics: Putting the 'E' Back into MSE through the Use of Design and Entrepreneurship," was the Young Leader Tutorial Luncheon Lecture offered by the second 2014 ECFF winner, Michele Viola Manuel. An assistant professor at the University

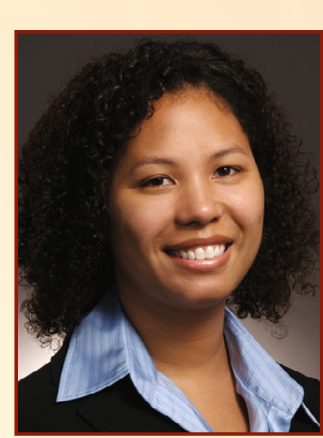

Michele Viola Manuel of Florida, Manuel leads the university's Materials Design and Prototyping Laboratory, focusing on research efforts dedicated to the design of advanced materials from high performance light metal alloys to self-healing alloy composites. She notes that her experiences as both an educator and researcher informed her lecture topic. "Materials science design is a new concept, and it is exciting to be part of shaping this emerging area," she said. "My talk offered the University of Florida perspective and our own ideas of integrating design from throughout the many disciplines supported by the university. Hopefully, this offered attendees some points and examples of how a university can approach this topic in a way that they are not accustomed to seeing."

Manuel will be chairing the Magnesium Technology Symposium at TMS2015 and is looking forward to the additional leadership opportunities within TMS that have been made possible by the ECFF award. "I am honored by the fact that my peers have recognized my potential," said Manuel. "Important milestones in a successful career often depend on people who see the promise in you that you sometimes can't see in yourself. This award is a reminder that it's not just you alone who achieves these goals, but a whole community of people who help get you there. To be honored in this way by people I may not even know is astonishing and humbling to me."

Nominations are being accepted through April 1 for the 2015 Early Career Faculty Fellow. For additional information and access to the nomination form, visit the TMS Professional Honors and Awards website at awards.tms.org. 